\title{
La ilusión de ser moderno (o el placer de la neofilia)
}

\author{
The illusion of being modern (or the pleasure of the neofilia)
}

$<$ Resumen>

La historia demuestra que el hombre no cesa en su afán de ser original. En efecto, las formas de expresión se conciben con la esperanza de ocupar un lugar de privilegio en la infinita línea del tiempo. Encabalgado a lomos del neoclásico, el Movimiento Moderno consiguió abrir su espacio propio y acuñó una inconfundible marca. Su esplendor eclipsó cuando las corrientes posmodernas reclamaron el lugar que les correspondía, a continuación

$<$ Abstract>

History teaches us that man never ceases in his quest for originality. Indeed, architectural forms of expression are conceived in the hope of obtaining a privileged place on an infinite time line. Overflowing in the wake of neo-classicism, the Modern Movement was able to open its own space and forge an unmistakeable niche. Its splendour was eclipsed when post-modern movements reclaimed the space that it should have inherited as a continuation.

<PALABRAS CLAVE>

ARQUITECTURA MODERNA / SIGLO XX /

PRIMER CENTENARIO / BICENTENARIO

<KEYWORDS >

MODERN ARCHITECTURE / TWENT IETH CENTURY / FIRST CENTENNIAL / BICENTENNIAL

\section{Introducción}

Algunos pueblos del norte de Chile no contaminados por las convenciones del predecible hombre actual tienen una peculiar visión de la vida. La conciben como un recorrido largo, en el cual el individuo camina de espaldas, nunca de frente: el pasado es aquella parte del paisaje o recorrido que vemos; el futuro es, en cambio, una vaga sensación que va adquiriendo consistencia poco a poco. Es lo desconocido, lo que se oculta a los ojos, pero se presiente, se adivina. ¿Qué hay detrás? Desde esa evanescente incertidumbre se va alumbrando el futuro, en una revelación paulatina, inexorable y fatal.

«Siempre llegarás a algún lado si caminas lo suficiente», le dijo a Alicia el Gato de Cheshire, en ese libro de Lewis Carrol, colmado de maravillas. En la búsqueda de un ideal, ¿la arquitectura habrá caminado lo suficiente? Es claro, sin embargo, que el prurito por el cambio es lo único constante. Mientras el tiempo transcurre el hombre se da maña para vestirlo con la moda. Pero es el propio tiempo el que se encarga de abolirla y rechazarla. Y la arquitectura no escapa a los mismos maretazos de transformación que experimenta el vestuario. Las ideas innovadoras buscan una pronta materialización en la producción humana. Por alguna razón, el blanco preferido de los creadores de formas hace foco en la industria de la ropa y en la arquitectura. Se puede escrutar en ellas los principios y motivaciones centrales de la sociedad, siempre ávida de novedades, cegada por la neofilia -el amor por la novedad-, disconforme con

\footnotetext{
Arquitecto Universidad de Chile (1971), convalidado en España (1981). Diploma en Restauración Arquitectónica y Urbana (Instituto de la Vivienda Español, Madrid, España, 1973). Curso Interamericano de Restauración de Bienes Culturales (Escuela Nacional de Conservación, Restauración y Museografía, México D.F., 1977-1978). Actualmente, Director del Instituto de Restauración Arquitectónica de la Facultad de Arquitectura y Urbanismo de la Universidad de Chile.

** Arquitecto Universidad de Chile (1996), estudios de Magíster en Urbanismo (1998-2000). Actualmente cursa el Programa de Doctorado en Arquitectura, FAU, Universidad de Chile / ETSAM-UPM España. Profesor Asistente InReAr FAU U. de Chile. Ha participado en diversos proyectos y consultorías de restauración arquitectónica, patrimonio y diseño.
} 
lo que tiene. Las convicciones y certezas, por lo general, son de vida corta. ¿Quién sabe, a ciencia cierta, hacia dónde enfilarán los futuros derroteros de la arquitectura? ¿Hace falta saberlo? Tal vez no. El Gato de Cheshire tenía la rara virtud de desaparecer de a poco, desde la cola hasta la sonrisa. Y era justamente esa sonrisa la que quedaba flotando, para estupor de la pequeña Alicia.

De espaldas al futuro sólo es posible percibir, suspendidos en el aire, unos vagos atisbos de la venidera arquitectura.

A dos años del Bicentenario de la Independencia, Chile se prepara para una celebración en grande. Y tal como hace cien años, la arquitectura juega un rol protagónico. Los códigos formales y estilísticos de entonces, visiblemente tributarios de las definiciones fraguadas en Europa, se materializaban en una arquitectura que se asimila al neoclásico decimonónico.

Hoy día la arquitectura en boga se hace llamar «contemporánea». Heredera del Movimiento Moderno, también resiste el apelativo de tardomoderna (Jencks, 1992) en sus espasmos más recientes. El mismo siglo $x x$ asiste al nacimiento y muerte de la Arquitectura Moderna, de la Arquitectura Racionalista, del Neo-brutalismo arquitectónico y de unas cuantas corrientes de vida efímera. Los proyectos se han sucedido y se seguirán sucediendo ${ }^{1}$, cada vez con más celeridad conforme el año 2010 esté más cercano. Una pantagruélica fiesta merece bocados edilicios memorables.

La familiaridad entre la «Arquitectura Contemporánea» y la que representa al Movimiento Moderno -también llamada «Arquitectura Racionalista»- es evidente. Desde luego, hay menos distancia conceptual y morfológica entre ambas que la que se advierte entre las corrientes que precedieron al Movimiento Moderno, tales como el estilo neoclásico y ciertas manifestaciones historicistas que evocan el floreciente pasado europeo.

Acerca de la arquitectura racionalista en Chile existe, en la actualidad, más bibliografía que obras vivas. El conocimiento de sus principios rectores y de sus exponentes se nos ofrece
Restaurante Cap Ducal, Viña del Mar (sitio web Colegio de Arquitectos)

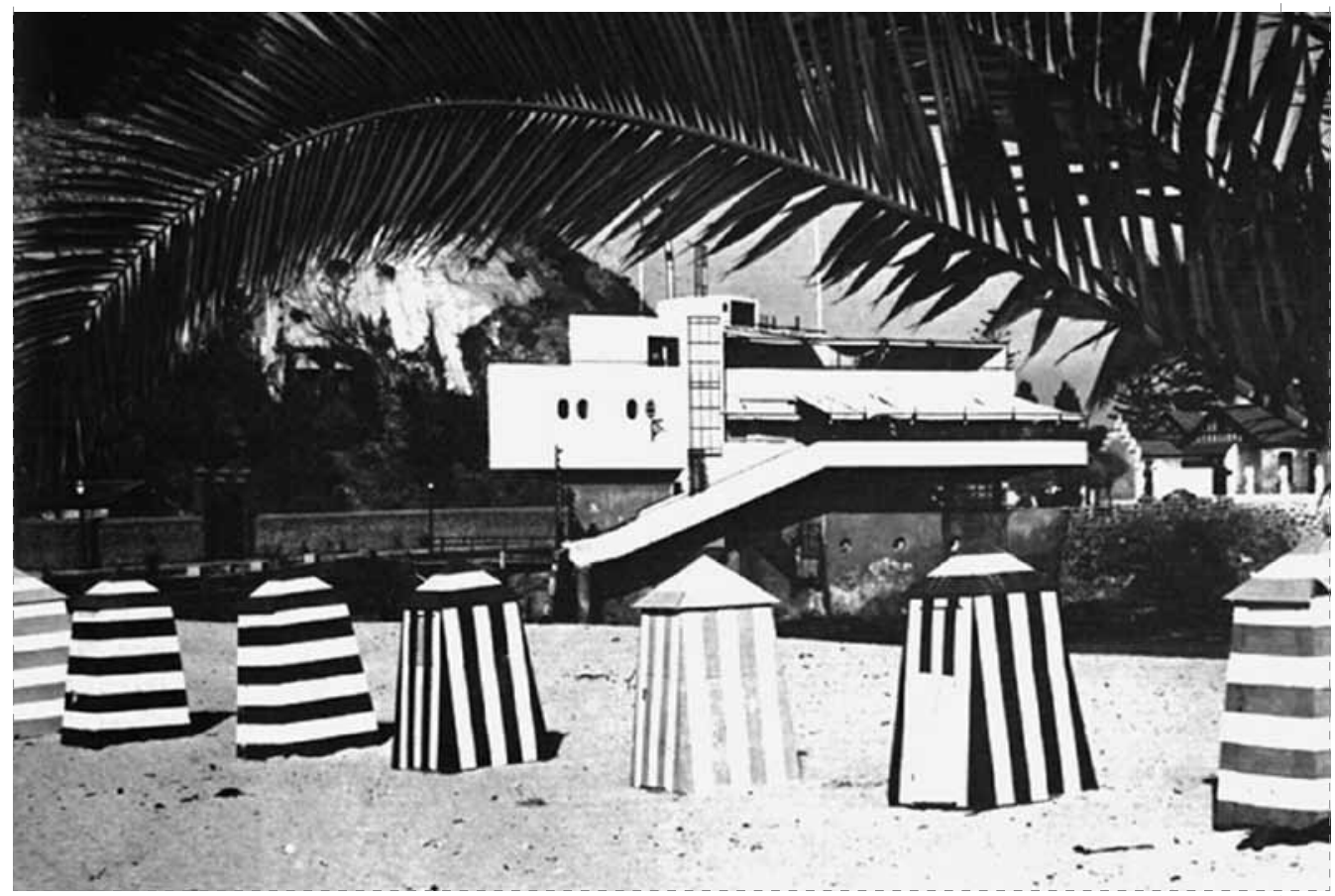

de una manera más bien indirecta. Virtudes y deméritos han sido tardíamente calibrados y, en buena parte de los casos, las demoliciones no tienen justificación posible. En la era presente no hay tiempo ni disposición para evaluar un bien antes de poner en marcha el bulldozer. Se sabe con exactitud el precio de los edificios, pero rara vez su valor. Es la tarea pendiente de las universidades y de los profesionales sensibles a la historia y al arte del buen hacer. Avanzamos de espaldas rumbo al futuro, dejando, frente a nuestros propios ojos, una estela de menosprecio exterminador, incubado en la audaz ignorancia. Tal vez también nosotros seamos víctimas de esa sonrisa suspendida en el aire del Gato de Cheshire, que se niega a precisarnos el límite entre lo valioso y lo fútil. Alzamos la vista y nos encontramos con unos dientes pequeños en forma de media luna, que se muestran en una socarrona mueca burlona. Pero, claro, la respuesta no está en el aire; a lo sumo hallaremos algunas voces casi inaudibles, como provenientes de un oráculo. Y es que la respuesta emerge después del análisis razonado y la observación sensible. De otro modo, contribuiremos a la desaparición de un trozo de pasado. Y también a la extinción de la identidad.

\section{Cambio de siglo, \\ fin de una ега}

A caballo entre los siglos xix y xx, Chile era un apartado país, cuya economía se centraba en la agricultura y la extracción de materias primas. La actividad industrial y manufacturera apenas gravitaban en el erario nacional ${ }^{2}$.

Mientras en Europa surgían las vanguardias (el Art Nouveau, la Secesión Vienesa, el Futurismo Italiano), en Chile las escuelas de arquitectura pugnaban por consolidarse como centros de enseñanza. La práctica de la profesión había dependido -y, en gran medida, seguía dependiendo- de arquitectos extranjeros, mayoritariamente franceses (aunque había de otras nacionalidades), avecindados en Chile: Claude François Brunet Debaines, Emilio Doyère, Lucien Hénault y Emilio Jequier, entre varios $^{3}$.

Incluso se podría pensar en una suerte de correspondencia entre proyectos decimonónicos, cercanos al Centenario, con otros materializados en vísperas del Bicentenario. A modo de ejemplo, a los Tribunales de Justicia -corresponde el Nuevo Complejo Judicial; a la Biblioteca Nacional, la Biblioteca Metropolitana; al Museo Nacional de Bellas Artes, el Centro Internacional de las Culturas (CIC) en la Plaza de la Ciudadanía-

Osvaldo Silva Galdames, Cristián Guerrero Lira. Historia de Chile. Tomo 5: Guerra del Pacífico a la Gran Depresión 1879-1931; pp. 40-51.

Un elemento positivamente desequilibrante para el erario nacional fue la incorporación de los ingresos por concepto de impuestos al salitre.

Wren Strabucchi. Publicación de Trabajos del Curso, Problemas y Tendencias Fundamentales en Arquitectura Contemporánea, Volumen I. 


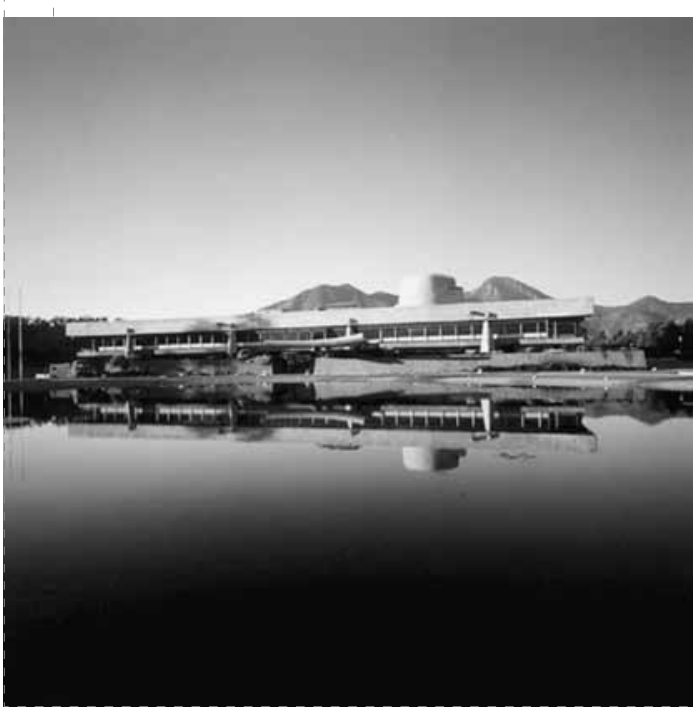

La llegada del Primer Centenario de la República fue la oportunidad propicia para celebrarlo con la inauguración de grandes y señeras obras de arquitectura. Algunas, cargadas de códigos propios de los revivals europeos; otras, concebidas en clave neoclásica. A la distancia pareciera que los proyectos generados en torno al Centenario marcaron el fin de una etapa creativa, la última gran expresión arquitectónica de una república parlamentaria cansada, que favorecía a la oligarquía terrateniente y empresarial de la nación.

Un relente de pesadumbre cargaba la atmósfera cultural en los albores del siglo $x x$. «Me parece que no somos felices; se nota un malestar que no es de cierta clase de personas, ni de ciertas regiones del país, sino de todo el país y de la generalidad de los habitantes», escribía Enrique Mac Iver ${ }^{4}$.

Tiempos en que el gobierno de Arturo Alessandri Palma aventuró un vuelco fundamental: representó al pueblo y el pueblo le apoyó. Aseguraba que su proyecto central se orientaba a favorecer a quienes consideró «mi querida chusma» ${ }^{5}$. En medio

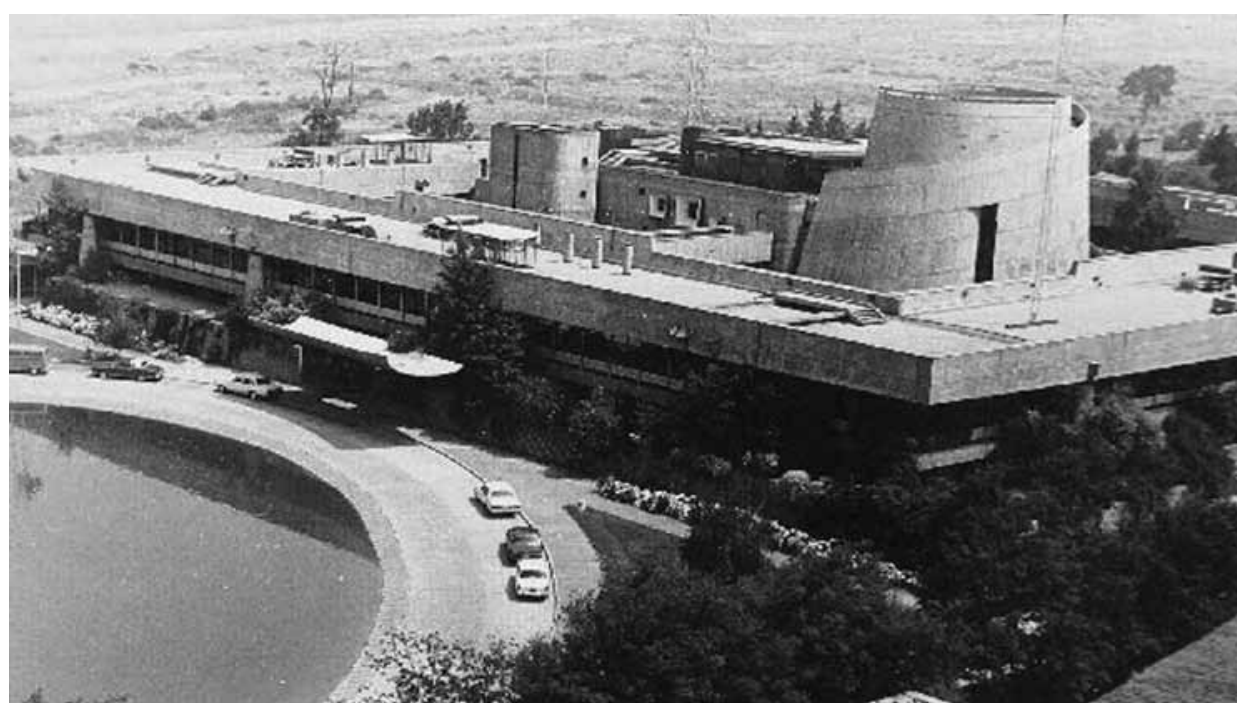

de su entusiasmo, a las masas proletarias y trabajadoras de la industria sumó otros grupos que no se integraban al patrón común de la multitud: inmigrantes, artesanos, comerciantes y profesionales de las más diversas disciplinas.

Más que los anuncios del nuevo siglo, la arquitectura del Centenario representa la clausura del siglo xıx y señala la eclosión del Movimiento Neoclásico en Chile.

\section{El paisaje de una nueva época}

El nuevo escenario arquitectónico que se genera a partir de la serie de gobiernos progresistas, inaugurado por Alessandri Palma, tendrá como actores a arquitectos de la talla de Sergio Larraín García-Moreno, Juan Martínez, Roberto Dávila y Enrique Gebhardt ${ }^{6}$.

Para algunos autores el Movimiento Moderno produjo dos corrientes de arquitectos: los de la transición entre dos siglos y aquellos que se identifican nítidamente con sus principios, convirtiéndose en sus verdaderos militantes y apóstoles.
Los arquitectos de transición, formados al amparo de la escuela más representativa del siglo xIx -el Beaux-Arts-, adoptaron los nuevos modos de hacer y de pensar la arquitectura, convencidos de saberse enriquecidos por la Francia decimonónica. No se trata de una adopción sin crítica, sin embargo; se tamizaba según las condiciones, posibilidades y tradiciones locales, dando origen a la llamada arquitectura neovernácula ${ }^{7}$

Los otros, los comprometidos a ultranza, propugnaban una posición más radical. Incentivados por el agudo déficit habitacional y la pobre infraestructura educacional, hospitalaria y cultural de entonces, se afanaron en tatuar el nuevo cuño en las creaciones en gestación. Enrique Gebhardt y Waldo Parraguez fueron sus representantes más preclaros $^{8}$.

Existe una cartografía ${ }^{9}$ que da perfecta cuenta de las sedes y lugares donde se operaba. Entre ellas se encontraban la Universidad Católica y la Universidad de Chile, el Colegio de Arquitectos, la Filial Chilena de los CIAM, La Revista Arquitectura y Construcción.

${ }^{4}$ Enrique Mac Iver. En: Silva Galdames, Op. cit.; p. 52

Enrique Mac Iver, Op cit. pp. 54-74.

6 Wren Strabucci. Op. cit:; vol. 1.

Enrique Browne C. Arquitectura contemporánea en América Latina. Tesis para optar al Título de Magíster en Planificación Urbana y Regional, Profesor Guía Sergio Larraín García-Moreno. Pontificia Universidad Católica de Chile. Santiago, diciembre de 1984

Browne se refiere a la arquitectura neovernácula como una situación de transición entre la arquitectura historicista y la arquitectura moderna.

8 Fernando Pérez Oyarzún. Publicación Taller VII de Investigación. Historia de la Historia. Arquitectura en Chile Textos e Imágenes, Tomos II.

Una importante preocupación de Gebhardt fue la difusión y el debate de la arquitectura moderna. En buena medida se debe a él la organización de la Exposición de Vivienda de 1939 y la fundación, junto a Waldo Parraguez, de la revista Arquitectura (1935-1936), primer medio dedicado a divulgar los principios en boga.

Hugo Mondragón López. Apuntes para una Cartografía de la Institución Arquitectónica en Chile, 1939-1952. Publicado en Actas. Patrimonio Moderno: $1^{\circ}$ Seminario DocomomoChile, Santiago, 5, 6 y 7 de octubre, 2005; pp. 18-29. 
Junto a estas sedes o lugares en los que se discutía acerca del significado y las implicancias del Movimiento Moderno, existían destinos ${ }^{10}$, esto es, los lugares de práctica o ejercicio de la arquitectura: desde el Estado y su institucionalidad y, también, desde el sector privado.

La Universidad de Chile, una de las sedes más fecundas, inauguró un curso de Arquitectura en 1849 -reformado en 1896-, inculcando fundamentos tecnológicos a sus estudiantes. Por su parte, la Universidad Católica fundó, en 1893, la carrera de Arquitectura, independizándose, un año más tarde, de la Facultad de Ingeniería.

Durante la primera mitad del siglo xx ambas universidades practicaron sus propias reformas: en la Universidad de Chile, el movimiento originado en 1933 propició un cambio en el plan de estudios de 1945, siendo decano Hermógenes del Canto. Notables fueron los frutos, presentados dos años después.

Análogamente, la Universidad Católica también tuvo su reforma. El nuevo plan concilió el modelo de enseñanza Beaux-Arts con otro más cercano a la Bauhaus. Dicha mixtura formativa perduró hasta 1952, cuando, tras la renuncia del Decano Alberto Risopatrón, asumió Sergio Larraín García-Moreno.

De manera paralela, la vida gremial tomaba forma. La Asociación de Arquitectos de Chile, gestada en 1923, devino, tras largas gestiones iniciadas en 1933, en la creación, por ley, de Colegio de Arquitectos de Chile, en 1942

Gran parte de la discusión sobre los cambios en la arquitectura tuvo su tribuna en la revista Arquitectura y Construcción, dirigida por Manuel Marchant Lyon ${ }^{11}$. Mientras tanto, los arquitectos imbuidos en el espíritu moderno ejercían indistintamente en el campo público o en el área privada.

En el ámbito público, fue providencial la asunción de Pedro Aguirre Cerda, en 1938, a la cabeza del Frente Popular, que optó por una transformación radical en materia de producción del país. Se trataba de estimular la industrialización, para lo cual se puso en marcha un ambicioso plan que consistió en la creación de empresas y servicios estatales, encabezadas por la CORFO (Corporación de Fomento a la Producción) ${ }^{12}$

La esfera privada, por su parte, se concentraba en el diseño de casas por encargo. En términos generales, las grandes inversiones se enmarcaban en proyectos cautelosos, casi convencionales. Se daba una relación inversamente proporcional entre la envergadura económica del proyecto y su grado de modernidad. Fueron, finalmente, los mandantes comparativamente más modestos (comerciantes de origen oriental, profesionale de libre ejercicio o directivos de empresas del Estado, por ejemplo), quienes aceptaron con más entusiasmo los proyectos de arquitectura moderna ${ }^{13}$. En el otro extremo, los mandantes de grandes residencias optaron, a menudo, por los estilos historicistas: neocolonial, neobizantino, neogótico, tudor o islámico ${ }^{14}$.

Por su parte, la práctica de la arquitectura pública -o desde el Estado-, se desarrollaba en las divisiones propias de cada organismo tuteladas por un Arquitecto Jefe. En materia de equipamiento, las responsabilidades recaían en instituciones como la Caja de Establecimientos Educacionales (1937) o la Caja de Establecimientos Hospitalarios (1944) entre otras. Y, muy especialmente, en el Departamento de Arquitectura de la Dirección General de Obras Públicas ${ }^{15}$.

Los aires de renovación recalaron en las organizaciones del Estado y terminaron por canonizar la arquitectura del Movimiento Moderno a partir de 1950. No puede sorprender que los equipos de proyectistas allí incorporados, con el acicate de los planes convenientemente reformados de las escuelas de arquitectura, hayan hecho suyo el manifiesto del CIAM, que destilaba vanguardia y revolución expresiva.
Edificio de viviendas frente al Cerro Santa Lucía (lapersonladelani_blogspot)

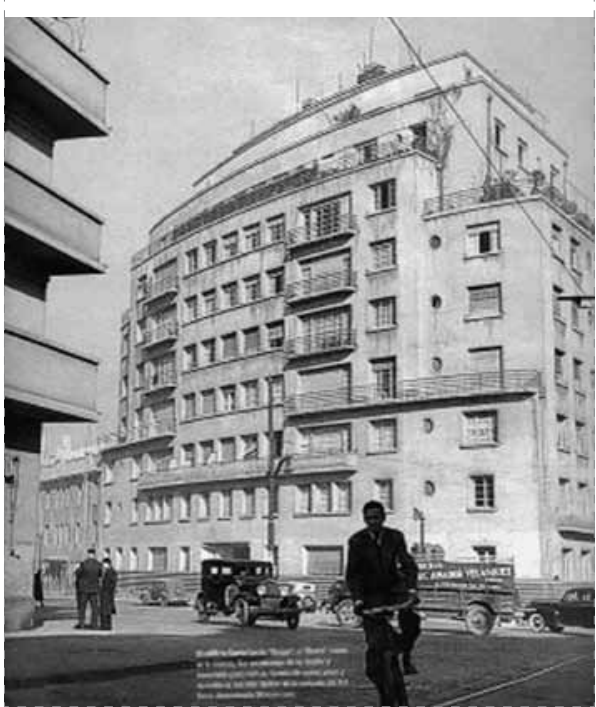

Pero el manifiesto debía traducirse en obras tangibles. Las búsquedas y exploraciones proyectuales continuaban siendo incesantes. Del llamado estilo internacional se reconocen los edificios «blanco estuco»; del período desarrollista, la arquitectura "gris hormigón». Hay quienes preconizaron, por su parte, «la otra modernidad», que recogía las tradiciones preindustriales del país ${ }^{16}$

A esta etapa corresponden algunas obras que la nómina de Monumentos Nacionales reclama para sí: la Universidad Técnica del Estado (BVCH, 1958-1965), el Edificio de la CEPAL y el de Naciones Unidas (Duhart y otros, 19601966); la Iglesia de los Benedictinos (Guarda y Correa, 1964)

\section{El ocaso de un sueño}

Los adalides del Movimiento Moderno habían hollado la carretera de la historia de la arquitectura, dejando su marca durante más de dos décadas ${ }^{17}$. Avanzando de espaldas, contemplando su propia obra y vanagloriándose de ella, no tenían por qué

10 Hugo Mondragón. Op. cit

11 Hugo Mondragón. Op. cit.

12 Durante los gobiernos radicales, especialmente durante la presidencia de Juan Antonio Ríos, la CORFO (Corporación de Fomento a la Producción) dio pie a la creación de una serie de empresas estatales: la Empresa Nacional de Electricidad (ENDESA, 1943), la Empresa Nacional de Petróleo (ENAP, 1946); la Compañía de Aceros del Pacífico (CAP, 1946), entre otras.

13 Osvaldo Silva Galdames, Cristián Guerrero Lira. Historia de Chile. Tomo 6: Entre Arturo Alessandri y Ricardo Lagos 1932-2004. Santiago: Editorial Universitaria, 2005; p. 11.

14 Andrés Téllez Talavera. La moda, el estilo y el cambio. En: La arquitectura doméstica de Santiago. 26 casas en Ñuñoa y Providencia 1935-1950. Santiago, 1995.

15 Osvaldo Silva Galdames, Cristián Guerrero Lira. Op. cit.; p. 11

16 Enrique Browne C. Op. cit.

«...a mediados de los 50 y durante los 60, cuando la arquitectura moderna protagonizó casi todos los emprendimientos públicos y privados que transformaron la imagen y formas de vida en las ciudades..... (Horacio Torrent. La memoria de lo Moderno. En: Revista Foco 76. Ideas de ciudad. Patrimonio Porvenir. Revista de Chilectra 2008: 6; pp. 24-27). 
Edificio Habitacional frente al Parque Bustamante

(Centro de Documentación de la Arquitectura Chilena, FAU, Universidad de Chile).

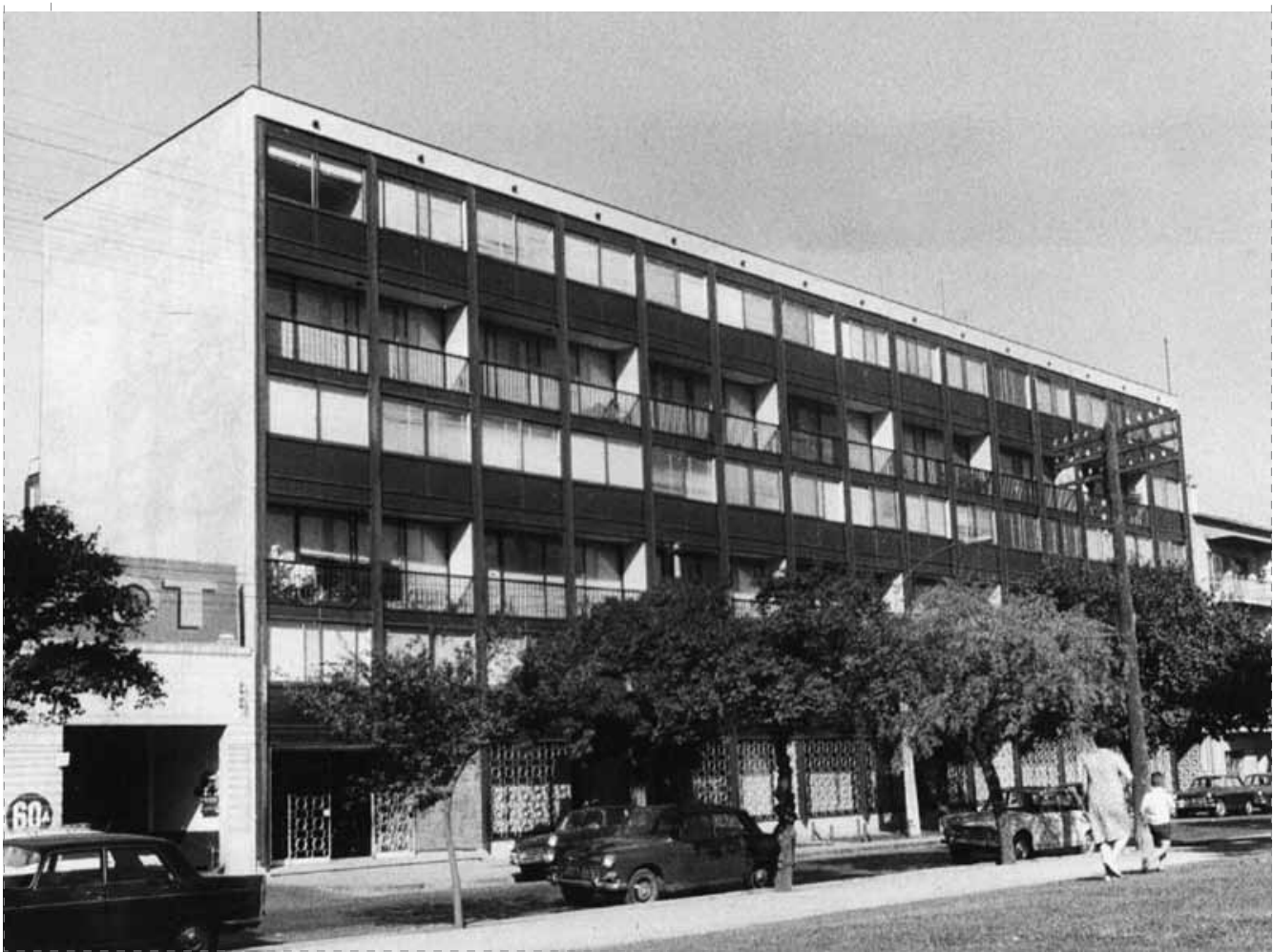

suponer que la barrera de contención estaba tan próxima. El fin lo presentían, sin embargo, a fuerza de reconocer que las modas tienen su fecha de vencimiento conforme dejan de ser propuestas innovadoras. Ya a partir de 1960 era dable intuir la decadencia en el inquieto hemisferio norte, a partir de la revalorización de la historia. Publicaciones como Complejidad y Contradicción en Arquitectura, de Robert Venturi (1966) y La Arquitectura de la Ciudad, de Aldo Rossi (1966) ${ }^{18}$ dieron el paso definitivo. En otro frente, los movimientos cismáticos propinaron su mirada crítica al pensamiento moderno: Archigram, el Metabolismo Japonés, Team $X^{19}$

Era inevitable: los ecos de ese fenómeno no tardaron en llegar hasta América. Bastó la conjunción de algunos factores sociales, políticos y culturales para que el proceso siguiera su curso hasta el cierre. En Chile, el desprestigio creciente del Movimiento Moderno tuvo como telón de fondo los gobiernos de Eduardo Frei Montalva y de Salvador Allende. Tiempos de guerra fría, de ideologización y de polarización extremas.

18 Fernando Pérez Oyarzún. Publicación Taller VII de Investigación. Historia de la Historia. Arquitectura en Chile. Textos e Imágenes. Tomos I y II. PUC, Santiago, 2006.

Keneth Frampton. Modern architecture. A Critical History (1851-1945). EE.UU.: Rizzoli, 1983.

\section{Epílogo}

A pocas décadas del desenlace de un difuso proceso en el cual el Movimiento Moderno abrió un boquete en la historia de la arquitectura universal, el balance es incierto. Para los artífices del sueño materializado en un amplio repertorio de obras, la indeleble marca constituye uno de los eslabones más valiosos de la cultura del siglo xx. Los abundantes detractores, a su turno, advierten en esta subversiva propuesta un cierto menosprecio por la calidad de la vida en la ciudad.

La presencia cada vez más determinante de la tecnología indujo el diseño simple, esquemático, de industrialización fácil, propiciados por los hijos del CIAM. Las artesanías, compañeras de los letárgicos procesos constructivos de las expresiones más elaboradas, no tenían cabida en la nueva concepción. Pero la realidad chilena no estaba para cambios tan radicales: por una parte, los progresos técnicos eran aún modestos en localidades distantes de la capital; por otra, la fuerza de trabajo existente no podía ser desechada sin transiciones. Resultado de ello fueron las tecnologías apropiadas.

Aun cuando la distancia temporal es aún insuficiente para discernir con irrefutable certeza la calidad de las obras, no cabe dudas de que muchas de ellas deberían integrar una nómina selecta. Obras que merecen formar parte del patrimonio universal. He ahí su condición de fragilidad: por no haber sido todavía oficialmente reconocidas, están expuestas a intervenciones desafortunadas o, simplemente, a la desaparición. Por eso, la necesidad de una visión historiográfica que incorpore el patrimonio del Movimiento Moderno se torna imperativa. En algunos casos, el peso del injustificado desprestigio asestado a los legados del CIAM conspira contra la conservación de edificios y conjuntos de alto vuelo creativo. Hasta el momento, la difusión y su valoración social han sido escasas. No es justo desconocer que uno de los factores que explican su persistencia fueron los moradores, un grupo humano dispuesto a participar de una experiencia enteramente desconocida.

Es un hecho que la ciudad ya no fue la misma tras el paso de esa suerte de tifón cultural conocido como Movimiento Moderno: una imagen renovada, irreverente, con abruptos cambios de escala. Una siembra de edificios perfectamente identificables en la hasta entonces sosegada trama urbana. 
Los efectos de este tifón no han sido del todo explicados. Su historia está aún por escribirse y las obras en proceso de evaluación.

Mientras tanto, seguimos inexorablemente rumbo al Bicentenario, caminando de espaldas para no perder de vista el pasado, siempre revelador y muchas veces insondable. Pero, ¿qué nos depara el futuro? ¿El péndulo va o viene?

Los dientes del Gato de Cheshire vuelven a dibujar la media luna de su socarrona sonrisa antes de desvanecerse.

\section{Bibliografía}

Max Aguirre González. La modernidad de la arquitectura y el papel de las revistas. En: Actas. Patrimonio Moderno: $1^{\circ}$ Seminario Docomomo-Chile. Santiago de Chile, 5, 6 y 7 de octubre, 2005; pp. 18-29.

Enrique Browne C. Arquitectura contemporánea en América Latina. Tesis para optar el Título de Magíster en Planificación Urbana y Regional, Profesor Guía: Sergio Larraín GarcíaMoreno, Pontificia Universidad Católica de Chile, Santiago, diciembre de 1984

Docomomo-Chile. Actas. Patrimonio Moderno: $1^{\circ}$ Seminario Docomomo-Chile. Santiago, 5, 6 y 7 de octubre de 2005.

Keneth Frampton. Modern architecture. A critical history. $3^{\text {rd }}$ ed. Londres: Thames and Hudson, 1996.

Andrea Masuero Espinoza. Plaza de la Constitución. Proyecto urbano y debate arquitectónico. Tesis para optar al título de Magíster en Arquitectura, Profesor Guía: Romy Hecht. Pontificia Universidad Católica de Chile. Santiago, septiembre de 2002.

Hugo Mondragón López. Apuntes para una Cartografía de la Institución Arquitectónica en Chile, 1939-1952. Publicado en: Actas. Patrimonio Moderno: $1^{\circ}$ Seminario Docomomo-Chile, Santiago, 5, 6 y 7 de octubre de 2005; pp. 18-29.

Manuel Moreno Guerrero et al. Publicación Seminario de Investigación: Arquitectura de los Sesenta en Chile. Cambio, Utopía y Disolución. Tomos I y II, Pontificia Universidad Católica de Chile, FABA, Escuela de Arquitectura, Santiago, Primer Semestre de 1997.

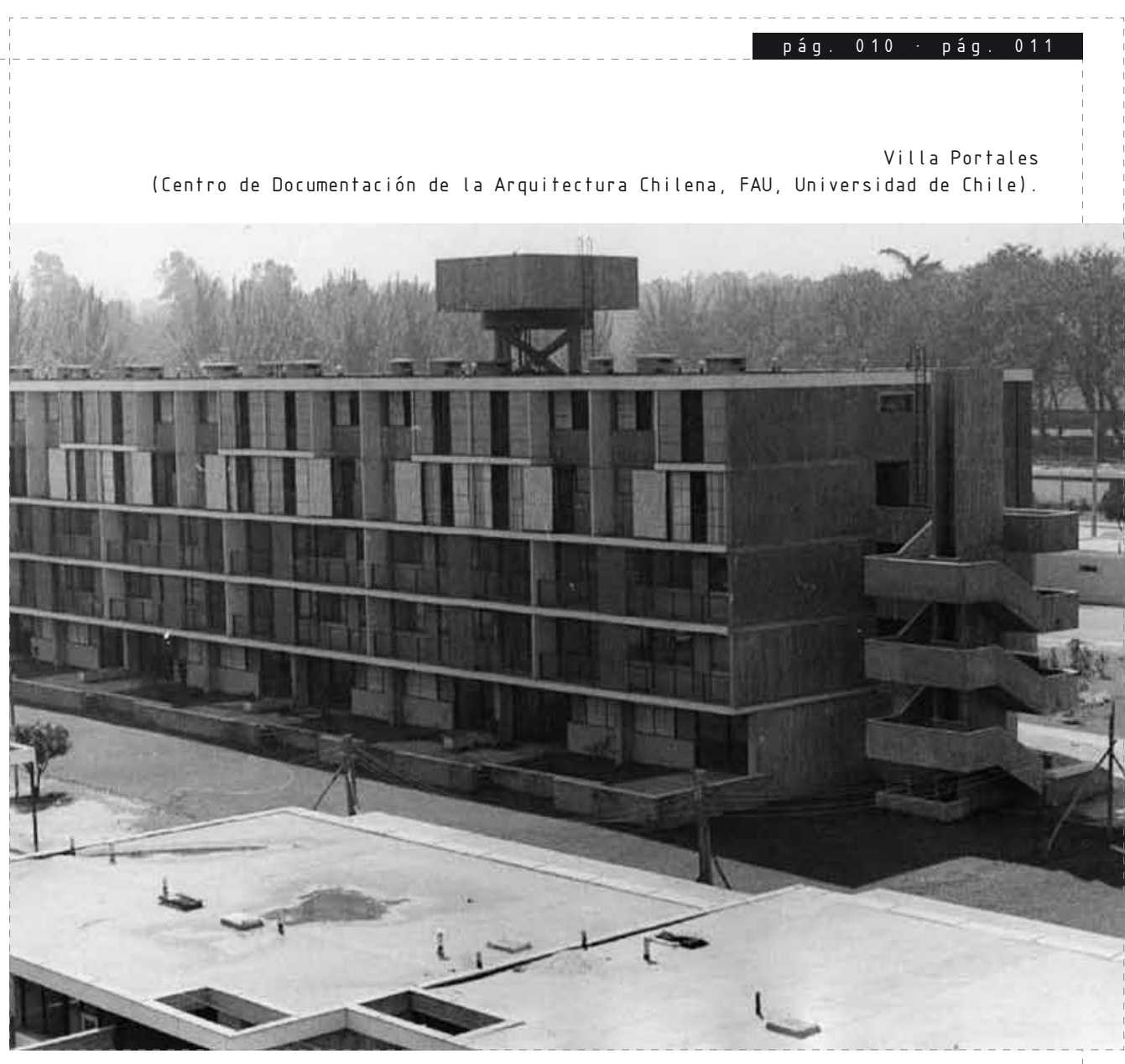

Manuel Moreno Guerrero, Horacio Torrent Schneider. Publicación de Trabajos del Curso Problemas y Tendencias Fundamentales en Arquitectura Contemporánea II. Escriben: Fernández, Andrés; Gaete, Mariela; Gross, Cristóbal; Heredia, Carolina; Kaiser, Paola; Lara, Giovanna; Medina, Nelson; Pezo, Mauricio; Schmitt, Álvaro; Stagno, Pietro; Vásquez, Julio. PUC Chile, FABA, Escuela de Arquitectura. Programa de Magíster en Arquitectura PUC, Santiago, 1996.

Fernando Pérez Oyarzún. Publicación Taller VII de Investigación. Historia de la Historia. Arquitectura en Chile Textos e Imágenes. Tomos I y II, Pontificia Universidad Católica de Chile, FABA, Escuela de Arquitectura. Santiago, Primer Semestre de 2006.

Osvaldo Silva Galdames, Cristián Guerrero Lira. Historia de Chile. Tomo 5: Guerra del Pacífico a la Gran Depresión 1879-1931. Tomo 6: Entre Arturo Alessandri y Ricardo Lagos 1932-2004.
Wren Strabucchi. Publicación de Trabajos del Curso Problemas y Tendencias Fundamentales en Arquitectura Contemporánea, Volumen I. Escriben: Olavaria, Juan Carlos; Sarovic, Marcelo; Valenzuela, Luis; Valenzuela, Silva; Vásquez, Juan Manuel: Zimmer, Claudia. PUC Chile, FABA, Escuela de Arquitectura. Programa de Magíster en Arquitectura Pontificia Universidad Católica de Chile, Santiago, 1993.

Andrés Téllez Tavera. La moda, el estilo y el cambio en la arquitectura doméstica de Santiago. 26 Casas en Ñuñoa y Providencia 1935-1950. Tesis para optar al título de Magíster en Arquitectura, Profesor Guía: Manuel Moreno, Pontificia Universidad Católica de Chile. Santiago, Chile, julio 1995.

La Gran Enciclopedia de Historia y Geografía de Chile. Santiago: Copesa Editorial SA, 2005. 